\title{
Characteristics of Thoracic Trauma in The Enrique Cabrera Hospital. Review of A Five-Year Period
}

\author{
Jorge Agustin Satorre Rocha ${ }^{1 *}$, Olga Caridad Leòn Gonzàlez ${ }^{1}$, Pedro Rolando López Rodroguez ${ }^{2}$, \\ Eduardo Garcia Castillo ${ }^{3}$ and Luis Manuel Danta Fundora ${ }^{3}$ \\ ${ }^{1} 1$ st grade specialist in general surgery and assistant professor in general surgery and auxiliary researcher, General Teaching Hospital, Cuba \\ ${ }^{2} 1$ st and 2 nd grade specialist in general surgery and consulting professor in general surgery and auxiliary researcher, General Teaching Hospital, Cuba \\ ${ }^{3} 1$ st year specialist in general surgery and assistant professor in general surgery, General Teaching Hospital, Cuba
}

*Corresponding author: Jorge Agustin Satorre Rocha, General Teaching Hospital “Enrique Cabrera, Cuba.

To Cite This Article: Jorge Agustin Satorre Rocha. Characteristics of Thoracic Trauma in The Enrique Cabrera Hospital. Review of A Five-Year Period. Am J Biomed Sci \& Res. 2019 - 5(4). AJBSR.MS.ID.000930. DOI: 10.34297/AJBSR.2019.05.000930.

Received: 㠿 September 22, 2019; Published: 眥 September 30, 2019

\begin{abstract}
Summary
Introduction. Thoracic trauma is common in today's society and of great importance Two to the nature of the organs that are located inside the thorax. Goals. Describe the characteristics of the patients admitted with the diagnosis of thoracic trauma. Methods It was made a Descriptive, retrospective and qualitative quantitative study, in which 102 patients were admitted to Enrique Cabrera Hospital with the diagnosis of thoracic trauma in the period from January 1, 2014 to December 31, 2018. Data from the medical records of the admitted patients were obtained. Results: Male (77.45\%) and ages between 40 and 49 years (25.49\%) predominated in the study. Traffic accidents were the most frequent cause of trauma $(31.38 \%)$, with predominantly thoracic trauma contused (63.73\%). The thoracic lesion caused by the most frequent trauma was the pneumothorax (44.11\%) and the most frequent extra thoracic lesions associated with the thoracic trauma occurred in the extremities (13.72\%), no lesions were associated in $66.75 \%$ of the patients. The surgical treatment was the most used being the Minimum Pleurotomy the most used (73.72\%). The most frequent complication was wound infections (13.72\%), in 58.82\%. of the patients there were No complications. $44.12 \%$ of the patients remained admitted for an interval of 5 to 10 days, this being the most frequent hospital stay. Conclusions. These results differ in some aspects when compared to other countries, which is given by differences in the economic and social order.
\end{abstract}

Keywords: Blunt and penetrating thoracic trauma; Minimum Pleurostomy; Thoracotomy

\section{Introduction}

Chest injuries were first described around $1600 \mathrm{BC}$ in the Edwin Smith Papyrus of Ancient Egypt. The writings of Hippocrates in the fifth century also contain a series of reports of trauma cases, including thoracic injuries. [1,2]. The surgical procedures of the thoracic conditions have evolved with the development of humanity since Hippocrates with its surprising operative techniques, Ambrosio Paré (1510-1570), one of the first to resort to the ligation of the great vessels Dominican Neo (S. XVIII) Initiator of the treatment of traumatic pneumothorax with the principle of aspiration. Johnione (1775), who described paracentesis as the last method that allows the effective exit of the accumulated air in the cavity, and so on until today [3]. In the nineteenth century, considerable progress was made in surgery with the modern drainage system under a water seal favored by mechanical artificial ventilation and the development of radiology that made possible the exploration of the pulmonary parenchyma and the improvement of thoracotomy [4].

In the last two decades, the management of thoracic trauma has progressed enormously especially Two to the development of diagnostic aids such as computed tomography, ultrasonography, magnetic resonance imaging and dynamic computed X-rays. In addition, advances in intensive care, emergency thoracotomy, video thoracoscopy, pain management and respiratory physiotherapy and the support of antibiotic therapy have influenced [5] Thoracic trauma constitutes a major public health problem and is the leading cause of death in people of productive ages in the world. In the United States, it is the fourth leading cause of death after coronary heart disease, cancer and cerebrovascular diseases, and it is estimated that $25 \%$ of trauma deaths are the result of thoracic injuries and that these constitute half of the overall mortality Two 
to trauma. In addition, it is estimated that for every person who This from trauma there are three injured, which translates into a great economic, moral and social cost [6-8].

In Cuba, accidents are among the leading causes of death, and chest traumas, often associated with accidents, represent 4 to $6 \%$ of hospital trauma revenues; its mortality is approximately $15 \%$ when lesions of internal organs of the thorax are present. $[9,10]$ The traumatized patient may present with injuries at any level, however, the chest is of particular interest because it is a frequently damaged area Two to its location and anatomical extension, as well as the presence of organs that make these lesions always considered potentially serious. (eleven) Thoracic trauma is all that occurs on the rib cage, lungs, heart, large intrathoracic vessels and other mediastinal structures. It is classified as blunt or penetrating, its frequency being dependent on the geographical site. Penetrating: Those in which there is a solution of continuity of the chest wall, with disruption of the visceral pleura, usually accompanied by laceration and bruising of the lung underlying Bruises: There may be a continuity solution in the skin of the chest wall (scoriations, wounds) but it does not penetrate into the thoracic cavity.

There may be an appointment of the musculoskeletal structures of the chest wall and / or intrathoracic organs by various production mechanisms: direct contusion, deceleration and shear mechanisms, or increased intrathoracic pressure. [11-14]. They usually occur as a result of car accidents, firearm projectile or shear puncture injuries, height drops or chest compression Two to crushing and usually of not need thoracotomy (80-85\%), with Pleurostomy treatment and medical treatment being the most frequent. Isolated studies describe changes in the clinical characteristics and epidemiology of thoracic trauma over time [15-17]. All of the above has motivated the authors to carry out this study with the objective of determining the behavior of thoracic trauma in the population that attends the Enrique Cabrera Hospital, where there are no records in this regard, in order to collaborate in the prevention and rapid therapeutic management of these patients and reduce morbidity and mortality, preventable in this type of trauma.

\section{Methods}

A descriptive, retrospective and qualitative quantitative investigation was carried out, in which 102 patients were admitted to the Enrique Cabrera Hospital, in the five-year period from January 2014 to December 2018, with the diagnosis of thoracic trauma. A System of Methods was used in the investigation, in which the Methodological Triangulation is revealed as an expression of the theoretical, empirical and statistical methods used. : The quantitative data obtained by analyzing the medical records of the admitted patients were processed with the statistical program SPSSPC (Stadistical Package for Social Sciences for Personal Computer Version for Windows XP Professional. Once the database was created, the analysis was performed with a simple frequency distribution and the percentages obtained in each case

\section{Results}

Table 1 shows that the age of $40-49$ with 26 patients (25.49\%) was the one with the highest number, followed by age 50-59 $(23.52 \%)$ and patients of the elderly 23 cases $(22.55 \%)$. Table 2 shows that the male sex was more frequent in our study 79 patients (77.45\%), the female sex was less 23 patients $(22.55 \%)$ In table 3 . According to the type of trauma, the contusion was 65 patients $(63.73 \%)$, the penetrating traumas being 37 patients $(36.27 \%)$. In table 4 . Traffic accidents with 32 patients (31.38\%) was the predominant cause, followed by stab wounds 30 patients $(29.41 \%)$, falls in general 28 patients (27.45\%), occupational accidents 6 patients (5.88\%), gunshot wounds 3 patients (2.94\%) and finally 3 other patients (2.94\%). En in table 5. Pneumothorax 45 patients (44.11\%), rib fractures 36 patients (35.29\%), hemoneumothorax $21(20.50 \%)$, hemothorax 17 patients $(16.66 \%)$, the pulmonary contusion 9 patients $(8.82 \%)$, were the most frequent thoracic lesions that caused admission. In Table 6. Injuries associated with thoracic trauma were more frequent in the limbs 14 patients (13.72\%) and the non-lesions associated with 62 patients $(60.78 \%)$ and abdominal injuries 13 patients (12.74\%). Abdominal.

\begin{tabular}{|c|c|c|}
\hline \multicolumn{3}{|c|}{ Table 1: Distribution of patients with thoracic trauma according to age. } \\
\hline Age, Groups and Years & No. Patients & $\%$ \\
\hline $18-29$ & 15 & 14,71 \\
\hline $30-39$ & 14 & 13,73 \\
\hline $40-49$ & 26 & 25,49 \\
\hline $50-59$ & 24 & 23,52 \\
\hline 60 and Over & 23 & 22,55 \\
\hline Total & 102 & 100 \\
\hline
\end{tabular}

Table 2: Distribution of patients with thoracic trauma by sex.

\begin{tabular}{|c|c|c|}
\hline Sex & No. Patients & \% \\
\hline Male & 79 & 77,45 \\
\hline Female & 23 & 22,55 \\
\hline Total & 102 & 100,00 \\
\hline
\end{tabular}

Table 3: Distribution of patients with thoracic trauma according to type of trauma.

\begin{tabular}{|c|c|c|}
\hline Type of Trauma & No. Patients & \% \\
\hline Contuse & 65 & 63,73 \\
\hline Penetraing & 37 & 36,27 \\
\hline Total & 102 & 100,00 \\
\hline
\end{tabular}

Table 4: Distribution of patients with thoracic trauma according to causes of trauma.

\begin{tabular}{|c|c|c|}
\hline Causes of Trauma & No. Patients & \% \\
\hline Traffic Accident & 32 & 31,38 \\
\hline Stab Wound & 30 & 29,41 \\
\hline Falls in General & 28 & 27.45 \\
\hline Works Accident & 6 & 5,88 \\
\hline Gunshot Wound & 3 & 2,94 \\
\hline Other & 3 & 2,94 \\
\hline Total & 102 & 100,00 \\
\hline
\end{tabular}




\begin{tabular}{|c|c|c|}
\hline Chest Injuries & No. Patienstes & $\%$ \\
\hline Pneumothorax & 45 & 44,11 \\
\hline Hemothorax & 17 & 16,66 \\
\hline Hemopneumothorax & 21 & 20,50 \\
\hline Pulmonary Contusion & 9 & 8,82 \\
\hline Lung Wound & 4 & 3,92 \\
\hline Vascular Lesiòn & 2 & 1,96 \\
\hline Rib Fracture & 36 & 35,29 \\
\hline Claviese Fracture & 8 & 7,84 \\
\hline Sternum Fracture & 1 & 0,98 \\
\hline Scapula Fracture & 1 & 0,98 \\
\hline
\end{tabular}

\begin{tabular}{|c|c|c|}
\hline Inflammatory Lung Disease & 3 & 2,94 \\
\hline Atelectasis & 2 & 1,96 \\
\hline No Complications & 60 & 58,82 \\
\hline
\end{tabular}

Table 9: Distribution of patients with thoracic trauma according to stay hospital.

\begin{tabular}{|c|c|c|}
\hline Days Internal & No. Patients & $\mathbf{\%}$ \\
\hline Less Than 5 Days & 40 & 39,21 \\
\hline From 5 to 10 Days & 45 & 44,12 \\
\hline More Than 10 Days & 17 & 16,67 \\
\hline Total & 102 & 100 \\
\hline
\end{tabular}

\section{Discussion}

Thoracic trauma classically occurs in young men with an

Table 6: Distribution of patients with or without trauma-associated injuries thoracic.

\begin{tabular}{|c|c|c|}
\hline Associated Lesions & No. Patients & $\mathbf{\%}$ \\
\hline Extremities & 14 & 13,72 \\
\hline Abdominal & 13 & 12,74 \\
\hline Craniocerebral & 4 & 3,91 \\
\hline Spine & 2 & 1,96 \\
\hline No Associated Injuries & 62 & 60,78 \\
\hline
\end{tabular}

In table 7. We see that the minimum Pleurostomy 75 patients $(73.52 \%)$ was the most used treatment in thoracic trauma, followed by 15 patients (14.71\%) non-surgical treatment. Table 8 refers to the complications of thoracic trauma. It shows that wound infection ranked first 14 patients (13.72\%), without complications 60 patients (58.82\%), reexpansion Pulmonary failure 10 patients (9.80\%), 7 patients (6.86\%) followed in coagulated hemothorax frequency, 6 patients pleural effusion (5.88\%), inflammatory patients 3 patients $(2.94 \%)$ and atelectasis 2 patients $(1.96 \%)$ In Table 9. It is appreciated that in the patients the hospital stays prevailed from 5 to 10 days 45 cases (44.12\%), followed in less than 5 days 40 cases (39.21\%) and in more than 10 days 17 cases $(16.67$ $\%)$, of the total of 102 patients.

Table 7: Distribution of patients with thoracic trauma according to treatment used.

\begin{tabular}{|c|c|c|}
\hline Treatment & No. Patients & $\mathbf{\%}$ \\
\hline Minimum Pleurostomy & 75 & 73,52 \\
\hline Thoracotomy & 12 & 11,77 \\
\hline Non-Surgical Treatment & 15 & 14,71 \\
\hline Total & 102 & 100,00 \\
\hline
\end{tabular}

Table 8: Distribution of patients with thoracic trauma according to complications.

\begin{tabular}{|c|c|c|}
\hline Complications & No. Patients & $\mathbf{\%}$ \\
\hline Wound Infection & 14 & 13,72 \\
\hline Pulmonary reexpansion not Satisfactory & 10 & 9,80 \\
\hline Coagulated Hemothorax & 7 & 6,86 \\
\hline Pleural Effusion & 6 & 5,88 \\
\hline Pleural Empyema & 4 & 3,92 \\
\hline
\end{tabular}
average age less than 40 years explaining this because they are the most physically and economically active ages with the greatest social development [18]. In the present investigation the fourth predominated decade of life (25.49\%), and also patients over 50 years since they were very incident falls as a cause of trauma, a result that differs from that obtained by Professor Jiménez, of the Sunday Luciani hospital in Caracas, Venezuela in which the thoracic trauma prevailed in the ages between 20 and 30 years. In a study carried out in Chile by Professor Bello, thoracic trauma was also found to be predominant at ages below those found in this work and also in a study carried out in Cienfuegos. [18-20] The male sex prevailed in the patients studied for being the most independent somebody and subjected to greater environmental noxes. All the national studies and hospitalizations reviewed coincide in the predominance in men. [21] The blunt trauma was the most frequent presentation, which coincides with most of the reviewed works. In different studies, mainly American and European, there is a predominance of blunt traumas, which reach up to 66-95.8\%, produced by traffic accident by vehicle motorized and falls, being more frequent the penetrating injuries in Latin American countries, produced by knife and firearms. [22-24].

The causes of penetrating or blunt trauma and its frequency vary mainly according to geographic location. In our case, traffic accidents predominated, followed by wounds caused by a knife with a frequency similar to falls in general. Similar results are reported in the United States and Europe, however in Latin America wounds Two to stab and firearms are more frequent. In a similar study conducted in the province of Cienfuegos, wounds caused by a knife were more frequent, followed by traffic accidents. [20,23,24] The injuries most caused by thoracic trauma were pneumothorax and rib fractures, which coincides with the literature consulted $[19,22,25]$. In a study conducted in Ecuador, hemothorax was the main diagnosis, followed by hemopneumothorax and pneumothorax; taking into account that the main cause was traffic accidents. [26]. In revised literatures, it is suggested that the pneumothorax is produced by the paper bag effect (pulmonary breaking when the glottis is closed before the shock) and are causes 
of injuries Two to tears or shear in frontal and lateral impacts. Romulo Valiant states that chest wall lesions can cause rib fractures with or without unstable chest, cardiac contusion, arrhythmias, pulmonary contusion and pneumothorax $[27,28]$.

In the majority of the authors reviewed, there was a predominance of isolated thoracic traumas over traumas with associated injuries and polytrauma, which coincides with our series, which implies a lower severity of the patients who are currently hospitalized for these traumas [23,29-31] In this study, among the associated lesions, the lesions in the extremities and abdomen predominated, which coincides with some authors consulted although others cite as more frequent craniofacial and abdominal lesions $[23,30,31]$ Surgical behavior prevailed as a treatment used, with minimal pleurostomy being the most used procedure, which coincides with the frequency of pneumothorax in this series and in accordance with other authors. Many studies indicate that despite the severity and morbidity and mortality associated with thoracic trauma, only $2.6-20 \%$ of them will need some major surgical intervention, with exclusive Pleurostomy being the main invasive method of treatment, followed by exclusive medical treatment. [23,31-33] More than half of the patients studied did not present complications Two to thoracic trauma.

These results could be related to the size of the treated lesion and the availability of means in the care center $[10,26,35,36]$ Among the complications presented, the most frequent were wound infections, which coincides with the literature reviewed. A study by Dr. Rigoberto Espinal and collaborators in Honduras of 184 patients with chest trauma reports that among the patients who presented complications predominated of infectious type, every effort should be made to prevent them with adequate initial treatment $[34,35]$. The hospital stays between 5 and 10 days was the one that prevailed coinciding with the largest number of uncomplicated patients in the series. In our series no deaths are reported. Some reviewed authors report more complicated patients and, of course, more hospital stays. prolonged, others show similar results to those obtained in this work, showing that although a large number of patients with chest trauma have to remain in the intermediate or intensive care rooms, connected to closed air systems, tend to quickly recover the pulmonary expansion and satisfactory recovery.

\section{Conclusions}

The group of patients from 40 to 49 years of age was the most frequent, with the male sex being the most frequent. The type of blunt trauma was the most frequent and traffic accidents the most frequent cause of trauma. The pneumothorax was the most diagnosed lesion at admission. Lesions in the extremities and abdomen were the most associated with thoracic trauma. The majority of patients had No associated lesions. The Minimum Pleurostomy was the most commonly used therapeutic procedure. Uncomplicated patients predominated and the most frequent complication was wound infections. Patients with a hospital stay of 5 to 10 days were the most reported.

\section{Conflicts of Interest}

There are no conflicts of interest.

\section{Reference}

1. Courtney M Townsend, David C Sabiston (2003) Sabiston: Manual of the surgery treatise (in Spanish). $17^{\text {th }}$ Edition, Published by Elsevier Spain, pp: 505.

2. Jaime Arias (2000) Medical-surgical nursing: Respiratory, cardiovascular, hemetological, endocrinological and breast pathologies (in Spanish). Published by Editorial Tebar pp: 48

3. Herodotus (1976) The nine books in history. Barcelona: Iberia pp: 131133.

4. Fahraeus R (1956) History of medicine. Barcelona: Gustavo Guilli.

5. Suarez T, Morales CH, Restrepo J, Orozco EH, Sanabria AE, et al. (2012) Chest ultrasound vs. chest ultrasound Multi-cut tomography in the diagnosis of post-traumatic hemothorax. Rev Colomb Radiol 23(2): 3465-70.

6. Cuts F, Buitrago F (2001) Chest Trauma. Rev. Fac. Med; 48 in: 35-44.

7. Miller TR, levi DT (2000) Cost-Outcome analisys in injury prevention and copntrol: eighty-four recente in the United State, Med care 38 (6): $562-82$.

8. Stewart M (1995) resuscitation in thoracic trauma. Br J Surg 82: 280284.

9. Morales Wong MM, Gómez Hernández MM, Ramos Godines A, González Folch R. (2008) Serious chest injuries and the approach of damage control. Rev Cubana Cir [Internet magazine]. 47(1): 10.

10. Castellanos González J, Leal Mursulí A, Adefna Pérez R, Izquierdo Lara F, Ramos Díaz N. (2011) Behavior of comprehensive thoracic trauma care. Hospital Miguel Enríquez (2006-2008). Rev. Cubana Cir [Internet magazine]. 50(2): 13p.

11. Rodriguez Loeches J (1990) Traumatic emergency injuries. City of Havana: Technical Scientific Editorial.

12. Demirhan R, Onan B, Oz K, Halazeroglu S (2009) Comprehensive analysis of 4205 patients with chest trauma: a 10-year experience. Interact Cardiovasc Thorac Surg 9(3): 450-453.

13. Dongel I, Coskun A, Ozbay S, Bayram M, Atil B (2013) Management of thoracic trauma in emergency service: Analysis of 1139 cases. Pak J Med Sci 29 (1): 58-63

14.Al-Koudmani I, Darwish B, Al-Kateb K, Taifour Y (2012) Chest trauma experience over eleven-year period atal-mouassat university teaching hospital-damascus: a restrospective review of 888 cases. J Cardiothorac Surg 35-42.

15. Kulshrestha P, Munshi I, Wait R (2004) Profile of chest trauma in a level I trauma center. I Trauma 57(3): 576-581.

16. Freixinet J, Beltrán J, Rodriguez P, Juliá G, Hussein M, et al. (2008) Severity indicators in chest trauma. Arch Bronconeumol 44 (5): 257-62.

17. Fernandez J (2012) Chest trauma. One-year experience. Medical Journal $3(4)$.

18. Ahumada V, Ottolino P, González A, Pinto F, Barrios R (2010) Severe Chest Trauma (TTS): experience at the Domingo Luciani Hospital: Caracas. VenezuelaCir Rev 63(4): 184-906.

19. Bello N, Bórquez P, Guridi R, Baeza A, Lilayú D (2005) Profile and management of chest trauma in a regional hospital. Rev Chil Cir 57(5): 393-396. 
20. Susan Paola Orozco Aguirre (2004) Chest trauma in the province of Cienfuegos. Three-year studio Medisur 12: 1

21. Westphal LF, de Lima LC, Correa J, da Silva J, dos Santos VL, et al. (2009) Thoracic trauma: analysis of 124 patients who underwent thoracotomy. Rev Col Bras Cir [revista en Internet] 36(6)

22. Brito Sosa G, Vivó Núñez JG (2012) Incidence of pneumothorax in the Hospital Julio Trigo López. Rev. Cubana Cir [Internet magazine] 51(1).

23. Roberto González L (2018) Chest trauma: characterization of hospitalizations for three decades. Research article. Rev Med Chile 146 196-205.

24. Liman S, Kuzucu A, Tastepe A, Ulasan G, Topcu S (2003) Chest injury due to blunt trauma. Eur J Cardiothorac Surg 23 (3): 374-378.

25. Mommsen P, Zeckey C, Andruszkow H, Weidemann J, Frömke C, et al. (2012) Comparison of different thoracic trauma scoring systems in regard to prediction of post-traumatic complications and outcome in blunt chest trauma. J Surg Res 176 (1): 239-47.

26. Vicente Corral Moscoso (2015) Chest trauma management and demo features. Hospital Cuenca -Ecuador. Original article. Rev. Fac. Cienc. Take it. Univ. Basin. December 33(3): 25-31.

27. Ali J, Adam R, Williams J, Bedaysie H, Pierre I, et al. (2001) Teaching effective ness of the trauma evolution and management (TEAM) module for senior medical students. J Trauma 52(5): 847-851.
28. Vaillan Soler Romulus (2004) Emergency And Emergency Trauma. $5^{\text {th }}$ ed. Technical Scientific Editorial, Cuba, Single Volume, Cap. Trauma torahgic pp: 11-30. Ali, J, R. Adams, J.

29. Roberto González L (2018) Chest trauma: characterization of hospitalizations for three decades. Rev. méd. Chile 146: 2.

30. Freixinet J, Beltrán J, Rodriguez P, Juliá G, Hussein M, et al. (2008) Severity indicators in chest trauma. Arch Bronconeumol 44 (5): 257-62.

31. El-Menyar A, Lafiti R, Abdul-Rahman H, Zarour A, Tuma M, et al. (2013) Age an traumatic chest injury: a 3-year observational study. Eur J Trauma Emerg Surg 39 (4): 397-403.

32. Al-Eassa E, Al-Marashda M, Elsherif A, Eid H, Abu-Zidan F (2013) Factors affecting mortality of hospitalized chest trauma patients in United Arab Emirates. J Cardiothorac Surg 8: 57-63.

33. Larrea Fabra, Martha Esther (2015) Chest and abdominal trauma: characterization: considerations for better diagnosis and treatment. Havana: University Editorial 586.

34. Borlase BC, Metcalf RK, Moore EE, Manart FD (1986) Penetrating wound to the anterior chest: Analysis of Thoracotomy and Laparotomy" The American Journal of Surgery 152: 649-653.

35. Rigoberto Espinal F (1992) Chest Trauma, Analysis of 184 Cases Honduran Medical Journal 60: 76. 